\title{
Realidade mediada: compreendendo qualidades restauradoras de ambientes através da fotografia ${ }^{1}$
}

\author{
Mediated reality: understanding restorative qualities of environments through \\ photography
}

\author{
Maíra Longhinotti Felippe ${ }^{2}$ \\ Ariane Kuhnen ${ }^{3}$ \\ Bettieli Barboza da Silveira ${ }^{4}$ \\ Camila Klein ${ }^{5}$
}

\begin{abstract}
RESUMO: O uso da técnica fotográfica tem atraído cada vez mais a atenção de pesquisadores no campo disciplinar da psicologia de modo geral e, especificamente, nos estudos das relações humano-ambientais, tais quais aqueles dedicados à investigação de ambientes restauradores: ambientes que permitem ou promovem a recuperação de recursos psicofisiológicos e sociais alterados pelas condições da vida cotidiana. Face às potencialidades de uso da fotografia nesse âmbito de estudo e à escassez de trabalhos sobre o tema no Brasil, o presente artigo objetiva apresentar a aplicação de técnicas fotográficas em duas investigações executadas em hospitais, acerca da capacidade restauradora de ambientes, e dedicadas ao exame da restauração a partir da condição de estresse. O Estudo 1 percorre o espaço de um hospital de custódia e tratamento psiquiátrico, localizado na Região Sul do Brasil, e discute a aplicação de imagens na função autofotográfica associada a entrevistas com funcionários da instituição. 0 Estudo 2 envolve pacientes pediátricos em quartos de internação de hospitais gerais no norte da Itália e apresenta a execução de entrevistas a partir da fotografia em sua função modelo. 0 artigo também introduz algumas modalidades de uso da fotografia em pesquisas psicológicas, possibilidades de análise, revisa aplicações da técnica fotográfica em estudos sobre ambientes restauradores e aponta potencialidades e limitações metodológicas relativas.
\end{abstract}

Palavras-chave: fotografia; ambientes restauradores; restauração; hospital; estresse.

ABSTRACT: The use of photographic techniques has increasingly attracted researches' attention in the disciplinary field of Psychology generally and, specifically, in the study of humanenvironmental relationships, such as those dedicated to the research on restorative environments: environments that allow or promote recovery of psychophysiological and social resources altered by the conditions of everyday life. Given the potential use of photography in this area and the lack of studies on the subject in Brazil, this article presents the application of photographic techniques in two investigations about the restorative capacity of environments. Such studies were performed in hospitals and examined the restoration from the stress condition. Study 1 examines the space in a custody and psychiatric treatment hospital, located in Southern Brazil, and discusses the application of images, which were produced by the participants, associated with interviews with staff of the institution. Study 2 involves pediatric

\footnotetext{
${ }^{1}$ Apoio financeiro: Coordenação de Aperfeiçoamento de Pessoal de Nível Superior - Capes.

2 Doutora em Tecnologia da Arquitetura pela Università degli Studi di Ferrara. Pesquisadora do Laboratório de Psicologia Ambiental (LAPAM) - Florianópolis, SC, Brasil. E-mail: mairafelippe@gmail.com.

${ }^{3}$ Doutora em Ciências Humanas. Professora do Departamento de Psicologia da Universidade Federal de Santa Catarina. Pesquisadora do Laboratório de Psicologia Ambiental (LAPAM) - Florianópolis, SC, Brasil.

${ }^{4}$ Mestre em Psicologia pela Universidade Federal de Santa Catarina. Professora Substituta do Departamento de Educação da Universidade Federal de Pelotas. Pesquisadora do Laboratório de Psicologia Ambiental (LAPAM) - Florianópolis, SC, Brasil.

${ }_{5}^{5}$ Mestre e Doutoranda em Psicologia pela Universidade Federal de Santa Catarina. Pesquisadora do Laboratório de Psicologia Ambiental (LAPAM) - Florianópolis, SC, Brasil.
} 
patients in general hospital inpatient rooms in North Italy and presents interviews from photographs used in a model function. The article also introduces some modes of photography use in psychological research, analysis possibilities, it reviews applications of photographic technique in studies on restorative environments and it points out their methodological strengths and limitations.

Keywords: photography; restorative environments; restoration; hospital; stress.

Embora o emprego da técnica fotográfica nas pesquisas psicológicas não seja novo ${ }^{1}$, a retomada do tema parece sempre necessitar advertir para outras possibilidades metodológicas que estejam além das mensagens numéricas e escritas, tão comumente utilizadas nas ciências sociais e humanas. Nesse sentido, a valorização da fotografia se deve a um conjunto de fatores, entre os quais: (a) o registro fotográfico media a realidade e produz um vínculo entre o observador e o conteúdo observado (Justo \& Vasconcelos, 2009); (b) pode potencializar depoimentos para além da imagem observada, fazendo comunicar as representações que os sujeitos pesquisados fazem de si e do meio (Justo \& Vasconcelos, 2009; Maurente \& Tittoni, 2007); (c) o uso de fotografias é especialmente importante para estudos que envolvem sujeitos com maior dificuldade de expressão, porque independe de habilidade escrita ou verbal (Neiva-Silva \& Koller, 2002); (d) por fim, imagens fotográficas têm o potencial de tornar o processo investigativo atraente ao participante (Loizos, 2002).

Por meio da análise de estudos psicológicos que fazem uso da fotografia, Neiva-Silva e Koller (2002) puderam identificar quatro funções principais na utilização do recurso, a saber: função de registro, função de modelo, função de feedback e função autofotográfica. $\mathrm{Na}$ função de registro, a fotografia é utilizada como instrumento de documentação de determinada ocorrência, não sendo relevantes para a pesquisa nem o autor, nem o observador das imagens, mas apenas o seu conteúdo. Nessa função, as fotografias podem ser utilizadas para o resgate do registro de uma época; para a comparação entre dois períodos distintos, como forma de apreensão de uma mudança histórica; ou mesmo, com a finalidade de capturar acontecimentos, efêmeros ou não, a serem resgatados em consultas futuras, a qualquer tempo (Loizos, 2002). Cita-se, por exemplo, o uso da fotografia associado a técnicas de observação, como a Observação de Vestígios Ambientais da Ação Humana, que consiste no exame dos sinais deixados pela utilização de um espaço (lixo, desgastes em materiais, grafitagem, etc.), acreditando-se na possibilidade de reconstrução do comportamento a partir das marcas geradas por ele (Pinheiro, Elali\& Fernandes, 2008).

Já na função de modelo, fotografias são apresentadas aos participantes da pesquisa, que comunicam suas percepções acerca da imagem que lhes é proposta. A atenção do pesquisador está voltada à reação de quem observa, em função do conteúdo observado (Neiva-Silva \&Koller, 2002). Kuhnen (2004), em estudo sobre as representações sociais do ambiente em moradores do Bairro Lagoa da Conceição, Florianópolis (SC), utilizou fotografias como modelos, que serviram de estímulo à fala dos sujeitos. São também exemplos de uso dessa função as técnicas de classificação, ordenamento e pareamento de fotografias (e.g. Hietanen \& Korpela, 2004; Hubbard, 1996), bem como avaliação de imagens por diferencial semântico (e.g. Gomes, Cavalcante \& Grinfeld, 2007).

Quanto à função de feedback, utiliza-se como modelo a imagem fotográfica do próprio participante da pesquisa, com o intuito de se poder perceber o efeito que ela produz sobre a autoavaliação do indivíduo, de acordo com determinado critério (Neiva-Silva \& Koller, 2002). Por último, o uso de imagens com a função autofotográfica possibilita a análise de 
fotografias produzidas pelo próprio participante da pesquisa, a pedido do pesquisador, sobre tema de interesse da investigação. Usualmente, seguem-se entrevistas nas quais os sujeitos partilham suas impressões acerca das imagens criadas e do próprio ato fotográfico em que estiveram envolvidos (Neiva-Silva \&Koller, 2002). Segundo expuseram Maurente e Tittoni (2007), durante as entrevistas, podem ser explorados os sentidos evocados pelas fotografias; os elementos escolhidos para registro e sua relação com o tema de estudo e o sujeito da investigação; os elementos que aparecem nas imagens e não foram citados pelos participantes; aspectos considerados relevantes para a investigação e excluídos das imagens produzidas; além de reflexões sobre o ato de fotografar. Nessa técnica, o foco recai tanto sobre o conteúdo das imagens criadas, quanto sobre o autor e observador das fotografias e suas percepções.

Através do método autofotográfico, os indivíduos recriam pela imagem o ambiente e suas relações com o mundo, uma vez que as fotografias produzidas por eles já não são mais mera cópia da realidade, mas uma elaboração realizada sobre dela, constituída de escolhas e modos de olhar. De acordo com Cavalcante e Maciel (2008), tal elaboração é uma construção individual produzida a partir de estímulos externos, que são processados, identificados e estão sujeitos às influências contextuais e experienciais da pessoa. Os autores se referiram a essa construção e seus significados como uma representação, fruto da ação e relação do sujeito com o meio, através das quais ele "constrói tanto o mundo quanto a si próprio" (p. 151).

Particularmente no que diz respeito à pesquisa no âmbito dos ambientes restauradores, ou seja, ambientes que permitem ou promovem a restauração de recursos psicológicos, fisiológicos ou sociais afetados pelas demandas cotidianas (Hartig, 2011), o uso da técnica fotográfica tem atraído cada vez mais a atenção de pesquisadores. Em busca realizada nas bases de dados Science Direct, Sage, Scielo e Pepsic ${ }^{2}, 20$ publicações envolvendo ambientes restauradores e fotografia foram encontradas, a partir de 2002, sendo metade delas dos últimos três anos (de 2014 a 2016). Esses estudos são, em sua maioria, provenientes dos Estados Unidos (5 contribuições), Itália (4 contribuições) e Reino Unido (4 contribuições), mas, também, da Finlândia (2), Suécia (2), Taiwan (2); além de Austrália (1), Canadá (1), Chile (1), Islândia (1) e Turquia (1). Nenhuma pesquisa nacional foi identificada a partir dos descritores utilizados (ver nota 2). Dentre os 29 departamentos acadêmicos informados como participantes desses estudos, 14 pertenciam às Ciências Humanas, com destaque para a Psicologia (11 participações) e 10, às áreas da Arquitetura, Urbanismo e Engenharias. Os setores disciplinares das Ciências Biológicas (2 participações), Administração (2 participações) e Saúde (1 participação) também estiveram presentes, embora em número menos expressivo.

Uma porção significativa dessas pesquisas se dedicou à investigação de respostas fisiológicasa diversos tipos de lugares (e.g. Chang, Hammitt, Chen, Machnik \& Su, 2008), bem como afetivas, tais como manifestadas no fenômeno da preferência (e.g. Colombo, Laddaga \& Antonietti, 2015; Hietanen \& Korpela, 2004; Korpela, Klementilä \& Hietanen, 2002; Lee, Williams, Sargent, Farrell \& Williams, 2014; Lindal \& Hartig, 2015; Tang, Sullivan \& Chang, 2015; Valtchanov \& Ellard, 2015; Watts, Khan \& Pheasant, 2016; White \& Gatersleben, 2011; White et al., 2010; Wyles, Pahl, Thomas \& Thompson, 2015), distinguindo-se a qualidade positiva de tais respostas frente aos chamados ambientes restauradores. Destacam-se também as investigações acerca da restauratividade percebida e das qualidades restauradoras percebidas em ambientes, comumente associadas aos estudos sobre 
preferência ambiental (e.g. Chang et al., 2008; Colombo, Laddaga, \& Antonietti, 2015; Felsten, 2009; Lee et al., 2014; Lindal \& Hartig, 2015; Nejati, Rodiek \& Shepley, 2016; Tang et al., 2015; Villagra-Islas \& Alves, 2016; White, Smith, Humprhryes, Pahl \& Snelling, 2011; White et al., 2010; Wyles et al., 2015). Outros trabalhos dedicaram-se ao exame dos tipos de atenção envolvidos frente a ambientes com características naturais ou construídas, bem como à investigação da capacidade ambiental de recuperação a partir da fadiga mental (e.g. Berman, Jonides \& Kaplan, 2008; Berto, 2005; Berto, Baroni, Zainaghi \& Bettella, 2010; Berto, Massaccesi \& Pasini, 2008; Lymeus, Lundgren \& Hartig, 2016).

A quase totalidade das pesquisas encontradas envolvendo ambientes restauradores e fotografia possuía delineamento experimental (19 em 20 estudos eram experimentais, apenas 1 qualificou-se como levantamento de dados) e todas faziam uso da fotografia na função de modelo, ou seja, as imagens eram elaboradas, selecionadas e propostas pelos pesquisadores como estímulos visuais para, por exemplo, a produção de efeitos restauradores, avaliações, respostas afetivas, fisiológicas e de atenção. Na maior parte dos estudos, as imagens foram apresentadas aos participantes por meio da tela de um computador (em 15 pesquisas), do tipo pessoal em modalidade online ou em situação de laboratório em universidades, mas também através de projeções em telão (em quatro pesquisas) ou mesmo impressões de pequeno ou grande formato (em três pesquisas).

Uma das discussões acerca do uso da fotografia em pesquisas psicológicas em geral e, especificamente, em pesquisas sobre ambientes restauradores pode recair sobre a capacidade das imagens de se sobreporem à realidade representada, ou seja, em que medida imagens fotográficas de lugares substituem ambientes reais na produção de respostas cognitivas, afetivas, fisiológicas e comportamentais. Nesse sentido, as pesquisas sobre ambientes restauradores utilizando cenários reais e cenários simulados têm convergido em seus resultados. Kjellgren e Buhrkall (2012), ao compararem os efeitos restauradores do contato com um ambiente natural real e com uma simulação do mesmo ambiente natural, encontraram que ambos foram igualmente eficientes em reduzir estresse tendo, todavia, o ambiente real produzido escores mais altos para o grau de estados de consciência alterados e energia (vitalidade) ${ }^{3}$. Também Valtchanov, Barton e Ellard (2010) destacaram os efeitos benéficos da imersão em ambientes naturais virtuais, como o aumento da presença de afetos positivos e a diminuição do estresse. Sabe-se da importância da imersão no processo restaurador: uma maior imersão em um ambiente mediado, dada pelo aumento do tamanho da imagem projetada, por exemplo, aumenta o potencial restaurador da simulação (Kort, Meijnders, Sponselee \& ljsselsteijn, 2006). De fato, Felsten (2009) encontrou níveis mais altos de restauração em ambientes internos de um campus universitário, quando foram utilizados grandes painéis de paisagens naturais de forte apelo estético, em oposição à situação em que apenas uma janela com visão limitada para a natureza era disponível. Aliada à discussão sobre realidade mediada e imersão, no estudo acerca de ambientes restauradores, outros autores também exploram a importância do realismo na produção da realidade virtual para a investigação do tema (Kort \& ljsselsteijn, 2006).

Diante do exposto, particularmente frente às potencialidades percebidas na aplicação de fotografias em estudos sobre ambientes restauradores, bem como face ao crescente interesse pelo uso dessa tecnologia em âmbito internacional e à escassez de trabalhos sobre o tema no Brasil - como observado em revisão de literatura - propõe-se, no presente artigo, apresentar a aplicação de técnicas fotográficas em duas investigações acerca da 
capacidade restauradora de ambientes. Ambos os estudos, um brasileiro e outro italiano, apresentados a seguir, respectivamente, como Estudo 1 e Estudo 2, foram executados em ambientes hospitalares e estiveram interessados na capacidade ambiental de restauração a partir da condição de estresse. A apresentação dos dados em paralelo propõe à comunidade científica um diálogo perante o uso da fotografia enquanto técnica de coleta de dados aliada à perspectiva ambiental. Objetiva-se lançar luz ao enlace proposto, expondo estudos convergentes sobre o constructo pesquisado e técnica utilizada. Nesse artigo, pretende-se enfatizar as potencialidades do uso da fotografia não apenas enquanto registro, extraindose, também, dados não verbais. Além disso, buscou-se enaltecer a importância do planejamento do ambiente hospitalar e as possibilidades de se rever a ambiência do lugar.

\section{Estudo 1: retratos da "loucura"}

O relato dessa investigação percorre o espaço de um hospital de custódia e tratamento psiquiátrico, localizado na Região Sul do Brasil. A instituição ocupa um território dentro de um complexo prisional, desse modo, conta com espaço restrito e permeado por outras unidades prisionais. Construído ainda na década de 1970, o hospital de custódia caracteriza-se por sua dualidade, o foco consiste em tratar pessoas que possuem diagnóstico de transtorno mental, mas que cometeram ato infracional. Apesar disso, também existem outras modalidades de atendimento, como os exames toxicológicos e os tratamentos provisórios de presos em surto psicológico. Atualmente, o hospital abriga cerca de noventa pacientes, amparados por aproximadamente cinquenta funcionários.

Na referida instituição, buscou-se investigar quais os aspectos físicos do ambiente de custódia hospitalar se ligam à percepção de efeitos restauradores. Para tanto, um dos recursos de coleta de dados utilizado foi a técnica de Fotografia do Ambiente (FA), haja vista seu potencial de desvelar através do retrato, uma linguagem marcada pela visualidade e enaltecida pela possibilidade de melhor compreender a relação pessoa-ambiente (Higuchi \& Kuhnen, 2008). A FA compõe o rol de possibilidades do modelo autofotográfico, pois cabe ao participante recriar, através da imagem, uma resposta sem palavras. Essa técnica foi complementada pela entrevista semiestruturada, visando um melhor resultado a partir do enlace das duas formas de acesso ao fenômeno.

\section{Aspectos metodológicos}

Os primeiros participantes do estudo foram funcionários do hospital com significativo conhecimento da vivência na instituição e considerados preciosas fontes de informação ou informantes-chave. Por se tratar de estudo com amostra intencional, os demais participantes foram convidados utilizando-se a técnica da bola de neve, que consiste em solicitar ao último respondente a indicação do respondente seguinte, até a saturação teórica dos dados.

A aplicação da técnica fotográfica dividiu-se em dois momentos, os quais serão chamados de Fase 1 e Fase 2. A Fase 1 iniciou-se com a abordagem ao participante. Neste momento, a pesquisadora expôs o objetivo da pesquisa, esclareceu dúvidas, questionou o respondente sobre a possibilidade de acesso a todo o território pertencente à instituição (necessário para a técnica fotográfica) e, diante do aceite, forneceu instruções acerca da utilização da câmera fotográfica. A cada participante foi solicitado que fizesse cinco 
fotografias, cada qual tirada individualmente diante de cada orientação. O roteiro para o registro autofotográfico foi o seguinte: (a) fotografia do lugar que mais gosta; (b) fotografia do lugar que menos gosta; (c) fotografia de um lugar de conforto; (d) fotografia do lugar mais estressante; (e) fotografia que represente o hospital de custódia. A pesquisadora acompanhava o participante até o local escolhido para a primeira fotografia e somente após o retrato passava-se à instrução seguinte.Ressalta-se que a maioria dos participantes tinha pleno domínio da câmera fotográfica, dispensando auxílio da pesquisadora em cada retrato efetuado. No entanto, nos casos em que o participante solicitava ajuda para manejar o equipamento, a pesquisadora executava a solicitação e voltava a se distanciar para não inferir no tempo e na escolha da foto.

A primeira fase concluía-se, para cada participante, com o término da elaboração das fotografias. Passava-se, então, à Fase 2 do estudo. No novo ciclo, as fotos produzidas em arquivo digital eram expostas individualmente na tela de um computador, de modo a permitira ampliação da imagem (o participante tinha autonomia para aproximar e distanciar a fotografia por meio do comando zoom) e possibilitar a condução de uma entrevista semiestruturada, que contasse com a lembrança recente do participante, também acerca das razões que o motivaram a escolher um ou outro lugar.Após a realização dos retratos fotográficos, pesquisadora e participante se reuniam em uma sala para a entrevista e apresentação das fotos. $O$ intervalo de tempo entre o término dos registros fotográficos e o início da entrevista foi em média de três minutos.

Com a exposição das fotografias na tela do computador, começava-se a indagação acerca das imagens. Nesse momento, a linguagem não verbal demonstrada em fotos era traduzida pelo próprio fotógrafo com palavras que expressavam sentimentos, argumentos e detalhes. Na entrevista, novamente, questionava-se sobre o livre acesso aos lugares em que o respondente quis elaborar suas fotos, sobre as dificuldades encontradas e sobre o manuseio da câmera. Posteriormente, a partir de um roteiro preestabelecido de quatro perguntas, o participante era questionado sobre: (a) o motivo de ter fotografado o lugar; (b) quais as características específicas do lugar o constituem como o ambiente que mais gosta/menos gosta/conforta/estressa/representa a imagem do hospital; (c) quais os sentimentos despertados ao fotografar o lugar; e (d) caso pudesse mudá-lo, que tipo de mudança faria.

Os questionamentos inerentes à Fase 2 foram observados cuidadosamente para que se encerrasse a etapa de coleta de dados. A observância se deu em razão da satisfação ou não dos objetivos do estudo a serem atingidos. Todas as entrevistas realizadas foram gravadas em áudio e posteriormente transcritas, o que possibilitou a atenção plena e o olhar dirigido ao participante. Ao final do percurso descrito, os dados foram analisados utilizandose a técnica de análise de conteúdo temático-categorial (Bardin, 1977).

\section{Resultados parciais}

Doze profissionais do hospital de custódia participaram diretamente no estudo. Desses, sete funcionários eram do sexo masculino. Cabe ressaltar que, devido à característica e cultura organizacional, a maioria dos colaboradores é composta por pessoas do sexo masculino. Do sexo feminino destacam-se profissionais do corpo técnico institucional alocadas nos setores de enfermagem, psicologia e assistência social. A média de tempo de trabalho na instituição informada pelos respondentes foi de 17 anos e 8 meses, 
sendo que o funcionário mais recente atuava há 3 anos e cinco meses, enquanto o mais antigo entrevistado trabalhava há 32 anos completos, por ocasião do estudo.

A primeira análise realizada a partir do material coletado refere-se aos lugares mais vezes escolhidos para a produção da fotografia, enaltecendo-se as predisposições de valência positiva ou negativa de cada lugar. Dentre as fotos do lugar de maior agradabilidade, destacou-se o pátio externo do hospital de custódia, escolhido por metade dos entrevistados.Trata-se de um local caracterizado por ser um espaço aberto, contemplar quadras para prática esportiva e, principalmente, por permitir contato com a natureza através de árvores, grama, vislumbre do sol e de um morro. Nota-se nas argumentações dos participantes grande entonação positiva ao citar os elementos naturais deste pátio, o que é muito compreensível haja vista o encarceramento na parte interna da instituição. Nesse sentido, o lugar de conforto também despertou bons sentimentos. A diferença, nesse caso, fica por conta da variedade de lugares fotografados, especificamente observada neste tópico. Percebe-se que o conforto foi constantemente atrelado ao local de trabalho (sala de atendimento/posto), de descanso (alojamento/cozinha), e a locais de interação social (recepção/pátio externo).

Quanto aos retratos sobre os disparadores desagradáveis e, portanto, ao encontro ao que se propõe como ambientes restauradores, destaca-se a "ala de tratamento", escolhida por metade dos entrevistados como o lugar que menos gostam. Essa mesma ala foi novamente lembrada por sete dos doze respondentes como o lugar mais estressante. De fato, as peculiaridades desse ambiente caracterizam sua subjetividade. Um emaranhado de grades, portas grossas de madeira, leitos pequenos e com pouca circulação de ar e aparecimento de sol o configuram como um "mau lugar". Nesse local, destaca-se a representação do "não lugar", uma vez que os internos neste espaço não estão em tratamento no hospital de custódia, e sim, em tratamento provisório para em seguida retornarem às suas unidades prisionais de origem.

Em relação às fotografias que simbolizavam a imagem que, para os entrevistados, representava o hospital de custódia, percebe-se uma predominância de escolhas para a fachada lateral da instituição. Nesse ângulo, cinco entrevistados procuraram contemplar em seus retratos uma placa com o nome do hospital, a porta de acesso principal, as grades nas altas janelas e na porta; as árvores que linearmente demarcam os limites do espaço, e parte do pátio externo. Nas demais fotografias, observam-se imagens do pátio defronte as enfermarias, da fila dos pacientes para consulta médica, retrato da horta do hospital e, por fim, do pátio externo.

A compreensão sobre as fotografias de conotação positiva (lugar que mais gosta/de conforto) e as de conotação negativa (lugar que menos gosta/estressante) é uma rica fonte de análise e informação. As significações e possibilidades de exploração acerca das características específicas de cada elemento contido nas fotos permite ao pesquisador imergir no contexto, apropriar-se do conteúdo e abraçar as tantas respostas e justificativas de escolha. Reforça-se, nesse momento, a capacidade de resguardar os porquês não questionados e verbalizados para potencializar as vantagens de se contemplar a linguagem não verbal.

No que tange aos dados referendados pela técnica de análise de conteúdo (Bardin, 1977), especifica-se neste estudo apenas o recorte que faz referência às respostas atreladas à técnica fotográfica. Nas 12 entrevistas transcritas, identificou-se que dos 68 elementos 
temáticos citados, alguns foram extensivamente nomeados, como é o caso de "grade", "paciente", "pátio externo", "ala de tratamento", "humanizar" e "espaço aberto". Esses seis elementos temáticos foram citados por todos os entrevistados em pelo menos um momento da entrevista.

Ao sintetizar a análise temática, percebe-se que, de modo geral, os respondentes atribuem alguns aspectos específicos para a estruturação de um ambiente restaurador no hospital de custódia, a saber: mais interação com a natureza; mais espaços abertos; número mínimo de grades e barreiras estruturais; mais atividades de estimulação cognitiva; maior interação social com o "mundo externo"; e localização do hospital em outro lugar, que não dentro de um complexo prisional. Segundo todos os entrevistados, o potencial de melhoria no tratamento dos pacientes em um lugar que denote saúde ao invés de justiça seria de grande valia para a restauração da saúde e bem-estar.

Quanto aos fatores que contribuem para o estresse e o desgaste psicológico de se estar e trabalhar neste ambiente, destacam-se os seguintes tópicos: tratamento provisório de pessoas presas em outras unidades prisionais; estrutura física antiga; tonalidades escuras das paredes; piso inadequado no chão do hospital; gestão administrativa da Justiça e não da Saúde sobre o hospital; defasagem de profissionais em todos os setores; inexistência de outra horta para trabalho terapêutico de pacientes; grades, barreiras e corredores estreitos. Tais ponderações foram apontadas pelos entrevistados como questões passíveis de mudança, não há a visualização de que melhorar esses quesitos seja algo utópico. Ao contrário, os próprios participantes enaltecem que o hospital percorreu grande avanço em humanizar seu serviço e tende a evoluir ainda mais, caso progrida para os moldes tratados pelas teorias que embasam a construção de ambientes restauradores.

\section{Estudo 2: a fotografia e o significado ambiental}

A segunda investigação de que trata este artigo também se deu em ambiente hospitalar, porém envolveu pacientes pediátricos com idade igual ou superior aos oito anos. Ocorreu em quartos de internação de três hospitais gerais pertencentes a duas diferentes regiões do norte da Itália. Seu objetivo central foi identificar as características físicas específicas de quartos hospitalares capazes de comunicar mensagens ambientais relacionadas à restauração afetiva do estresse, ou seja, a recuperação de estados afetivos mobilizados por reação de estresse. As técnicas fotográficas utilizadas nesta investigação foram associadas à entrevista semiestruturada e propuseram-se à satisfação do objetivo específico de identificar a correspondência entre atributos físicos do ambiente e seus significados.

\section{Aspectos metodológicos}

As fotografias empregadas assumiram nesta pesquisa a função de modelo: foram estímulos apresentados aos participantes para que estes comunicassem suas percepções acerca das imagens que lhes tinham sido propostas. Ao todo, onze imagens de quartos de internação produzidas em um momento anterior da pesquisa foram utilizadas (ver Figura 1). Tais imagens são representativas dos quartos de internação presentes na investigação: uma imagem de cada tipologia de quarto foi selecionada para formar o grupo de estímulos fotográficos. Elas foram impressas a cores em papel fotográfico de dimensões 7 por $10 \mathrm{~cm}$ 
(orientação paisagem), posteriormente laminadas com adesivo transparente fosco e coladas sobre um suporte rígido imantado com as mesmas dimensões da imagem e espessura de 3 $\mathrm{mm}$. Foram dispostas aleatoriamente sobre um quadro magnético 40 por $60 \mathrm{~cm}$ (espessura de $1,5 \mathrm{~cm}$ ), de cor branca, e apresentadas aos pacientes, individualmente, durante uma entrevista.

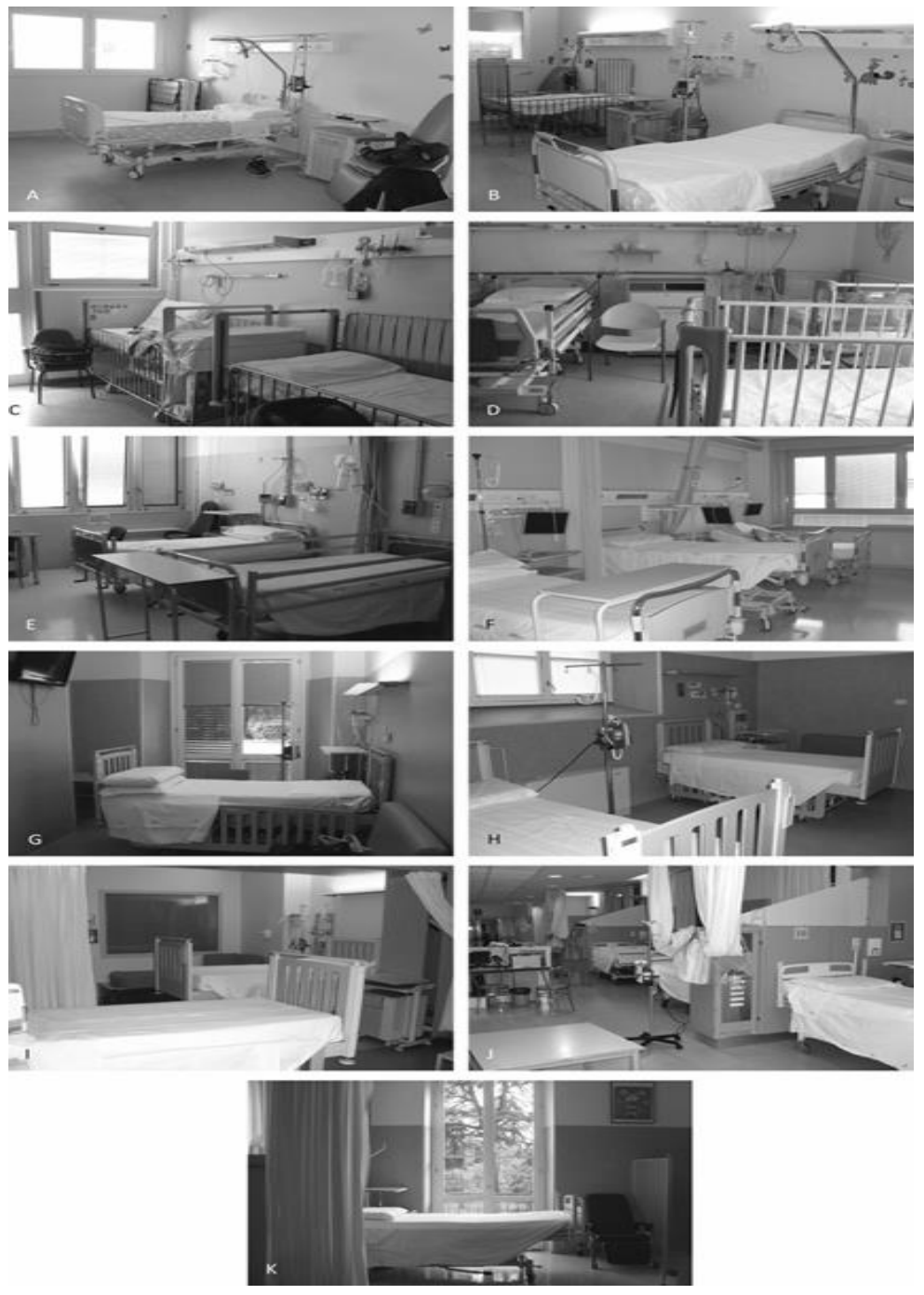

Figura 1 - Imagens utilizadas na classificação e no ordenamento de fotografias (originais a cores).

A entrevista foi realizada a partir de questões abertas, previamente elaboradas pelo pesquisador, a partir de resultados obtidos em uma fase anterior da investigação(referência ocultada para evitar identificação dos autores na avaliação às cegas). O roteiro de entrevista utilizado foi o seguinte:

Aqui estão diversas fotografias de quartos de internação. Podes arrastá-las sobre o quadro magnético como quiseres. Gostaria que tu observasses atentamente todas as imagens e me dissesses quais fotografias representam para ti um quarto de internação belo. Entre todas as fotos, podes escolher quantas quiseres e arrastá-las ao centro do quadro magnético.

Uma vez que o paciente tivesse selecionado as fotografias, seguia a pergunta: "Para ti, quais aspectos físicos tornam belos estes quartos? Podes falar sobre cada foto ou de modo geral". Assim que o paciente tivesse respondido a pergunta, o pesquisador solicitava: "Poderias ordenar os quartos que escolheste do mais belo ao menos belo?". A partir desse 
ponto, a entrevista prosseguia com a mesma sequência de questões, porém, no lugar de belo, inseriam-se outros adjetivos relevantes para a investigação, a saber: (a) calmo, tranquilo, relaxante; (b) cômodo, acolhedor, onde se está bem, à vontade, e onde as pessoas se sentem livres, não oprimidas; (c) alegre, vivaz, interessante e divertido; (d) tranquilizador, que faz sentir protegido, amado. Por exemplo:

Agora gostaria que identificasses entre todas as fotos aquelas que representam para ti um quarto de internação calmo, tranquilo, relaxante. Para ti, que aspectos físicos tornam relaxantes estes quartos? Poderias ordenar os quartos que escolheste do mais relaxante ao menos relaxante?

As perguntas "Que fotografias representam para ti um quarto de internação belo?" e "Poderias ordenar os quartos que escolheste do mais belo ao menos belo?" correspondem a duas técnicas fotográficas de investigação denominadas, respectivamente, classificação e ordenamento de fotografias (ver Cavalcante \& Maciel, 2008). A técnica de classificação de fotografias consiste em apresentar um conjunto de imagens fotográficas aos participantes, solicitando que organizem essas imagens em grupos, segundo os critérios estabelecidos pelo pesquisador ou segundo seus próprios critérios. A técnica de ordenamento de fotografias, a sua vez, consiste em solicitar aos participantes que disponham em ordem crescente ou decrescente as imagens apresentadas, segundo um critério determinado, com o objetivo de avaliar a relação que os respondentes estabelecem entre as imagens (Cavalcante \& Maciel, 2008).

Os dados obtidos por meio das técnicas de classificação e ordenamento de fotografias foram registrados pelo pesquisador, no momento da entrevista, em uma planilha de anotações, uma para cada paciente. Na referida planilha, a cada pergunta, eram assinaladas as imagens escolhidas pelos participantes e registrada a sequência do ordenamento realizado. Todas as entrevistas foram gravadas por meio de aparelho de áudio digital. Cada paciente respondeu às questões na posição de sua preferência, sobre o leito ou sentado a uma mesa. Ao participante foi oferecida a possibilidade de segurar o quadro magnético com as fotografias, se assim preferisse. Caso contrário, o pesquisador o fazia à sua frente. Demonstrou-se ao paciente como ele poderia arrastar as imagens imantadas sobre a plataforma magnética, organizando-as de modo a responder às questões da entrevista. Nessa investigação, o tempo médio de duração de cada entrevista foi de 9 minutos e 33 segundos (sendo o tempo mínimo de 5 minutos e 42 segundos, e o tempo máximo, 17 minutos e 6 segundos). Todo o material de pesquisa (quadro magnético e fotografias laminadas imantadas) foi acuradamente higienizado com álcool em gel 70 graus, antes e após cada entrevista.

As respostas gravadas por meio de aparelho de áudio foram transcritas em meio digital e analisadas segundo análise de conteúdo temático-categorial, como proposto por Bardin (1977). Os dados da classificação e do ordenamento de fotografias anotados em planilha foram tabulados e submetidos à análise estatística descritiva, por meio de frequências, bem como análise relacional, com auxílio do programa StatisticalPackagefor Social Sciences (SPSS). O Chi-Quadrado de uma variável ou teste de aderência foi executado com o objetivo de avaliar se as frequências de citação observadas diferiram significativamente daquelas que poderiam ser esperadas. Através das análises, foi possível identificar quais quartos de internação e componentes físicos específicos contribuem à comunicação de certos significados ambientais e a ordem de importância que assumem em comunicar tais significados. Serão apresentados, no presente relato, apenas os resultados relativos ao 
primeiro conjunto de questões da entrevista, com o objetivo de ilustrar algumas possibilidades de análise a partir das técnicas de pesquisa utilizadas.

\section{Resultados parciais}

Cinquenta e cinco pacientes internados responderam às entrevistas, sendo 33 do sexo masculino. A média de idade dos participantes foi de 12 anos e 9 meses ( $D P=2$ anos e 11 meses), sendo a idade mínima de 8 anos e 7 meses e a máxima de 22 anos e 5 meses.

O primeiro conjunto de questões fez referência a características de quartos de internação belos. A cada entrevista, o número de fotografias de ambientes percebidos como belos, escolhidos dentre as onze imagens propostas, variou de 1 a 11 (todas as fotografias foram selecionadas ao menos uma vez), sendo 3 o número mais frequente. Os quartos de internação mais indicados nesta questão foram aqueles identificados com as letras I, G, K e J (ver Figura 1), mencionados em 43, 29, 21 e 20 entrevistas, respectivamente, sendo responsáveis por $60,11 \%$ do total de 188 citações. Os demais quartos foram apontados por 15 ou menos participantes, sendo o quarto B aquele com o menor volume de menções (2,66\% das citações, escolhido em apenas 5 entrevistas). O primeiro gráfico ilustrado na Figura 2 apresenta as frequências absoluta e relativa de citação de cada quarto, obtidas por meio da técnica de classificação de fotografias para a qualidade beleza.

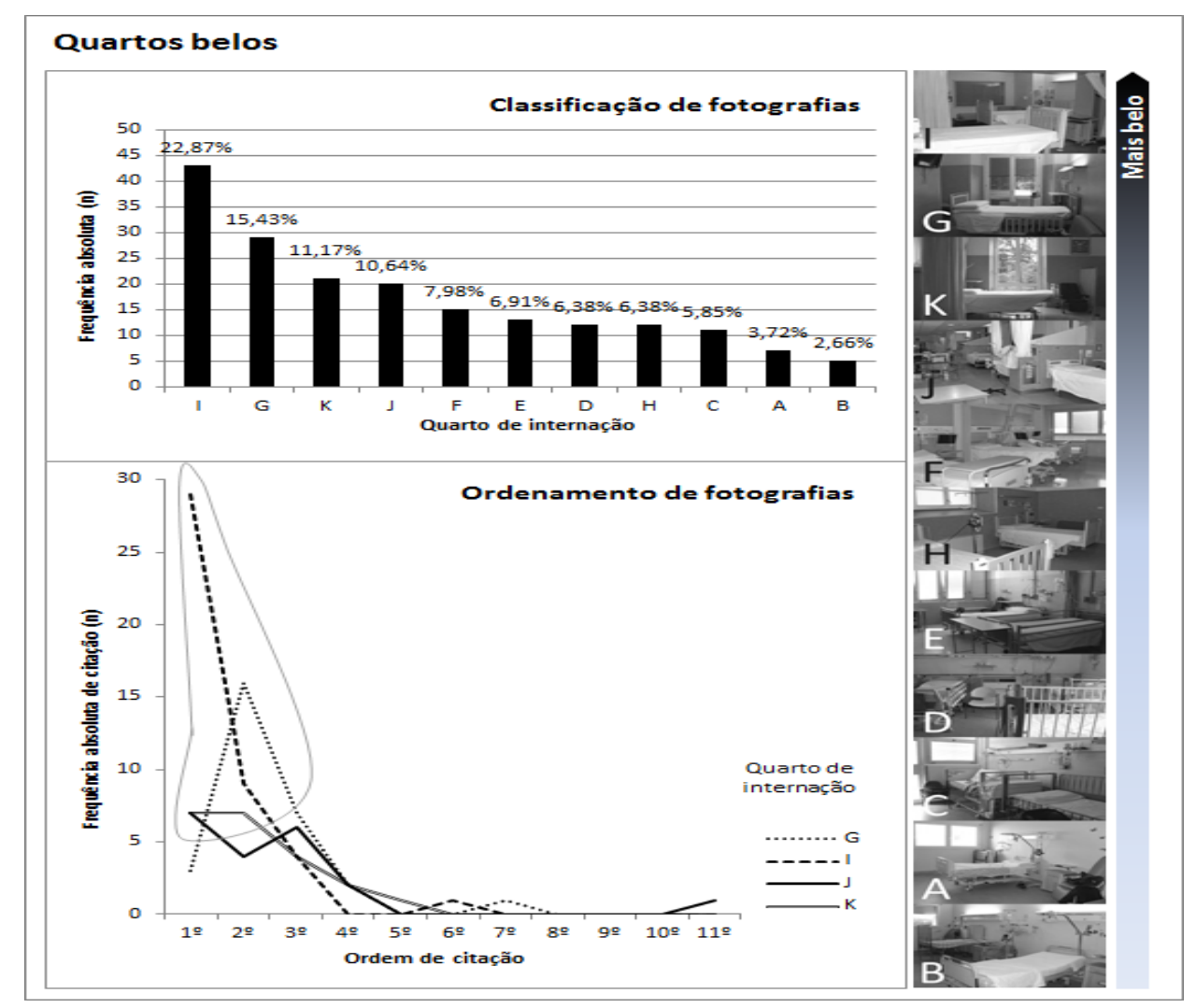

Figura 2 - Resultados da classificação e do ordenamento de fotografias para quartos de internação belos. 
O Chi-Quadrado de uma variável foi executado com o objetivo de avaliar se as frequências de citação observadas diferiram significativamente daquelas que poderiam ser esperadas caso não houvesse diferenças entre os quartos quanto ao quesito beleza, ou seja, caso todos os quartos fossem igualmente belos ou igualmente feios. $O$ valor de $\chi^{2}$ de 31,40 com grau de liberdade 9 e probabilidade associada menor que 0,001 foi encontrado, indicando que existe uma diferença estatisticamente significativa entre as frequências observadas e esperadas: isto é, os quartos de internação apresentados não foram igualmente belos na percepção dos pacientes. Mais participantes consideraram belos os ambientes representados nas fotografias I, G, K e J, em detrimento dos demais ambientes. Para esses quartos, de acordo com o teste de aderência, as frequências relativas de citação observadas superaram aquelas que poderiam ser esperadas $(10 \%)$, caso a hipótese nula fosse verdadeira.

Os dados obtidos por meio do ordenamento de fotografias confirmaram os resultados alcançados através da técnica de classificação: mais da metade das vezes em que foram citados, os ambientes I, G, K e J ocuparam a primeira ou a segunda posição do ordenamento fotográfico, estando entre os mais belos na opinião dos respondentes. Isso não ocorreu para as demais imagens, que tiveram metade ou mais da metade das menções ocupando a partir da terceira posição do ordenamento. 0 segundo gráfico da Figura 2 ilustra a frequência absoluta de citação dessas quatro imagens em cada uma das posições do ordenamento fotográfico. A linha cinza nesse gráfico evidencia a região correspondente ao maior número de citações nas primeiras posições.

A partir dos dados do ordenamento de fotografias, foi possível construir uma escala de beleza envolvendo os onze ambientes apresentados, do mais belo ao menos belo, segundo a percepção dos pacientes entrevistados. Para tal, as frequências de citação das fotografias foram ponderadas de acordo com a posição no ordenamento, desta forma: citações na primeira posição receberam um peso maior (peso 11 ) que as citações na segunda posição (peso 10); citações na segunda posição receberam um peso maior que as citações na terceira posição (peso 9), e assim por diante. O somatório das frequências ponderadas determinou a posição de cada fotografia na escala de beleza, de modo que as fotografias com o maior número de citações nas primeiras posições ocuparam os primeiros postos dessa escala, que pode ser consultada no canto direito da Figura 2.

Para compreender os motivos que nortearam as escolhas dos participantes, perguntou-se que atributos físicos tornavam belos os quartos de internação selecionados. A análise de conteúdo das 55 respostas a essa questão identificou 52 elementos temáticos em um total de 173 presenças e 201 ocorrências. O número máximo de ocorrências por respondente foi igual a 13 e o número mínimo, igual a 1 . Os elementos temáticos mais presentes foram "cores laranja-avermelhadas", "porta-janela ampla" e "espaçoso", indicados por 25, 15 e 11 pacientes, respectivamente. Juntos, estes elementos foram responsáveis por 54 ocorrências (26,87\%).

Por meio da síntese temática realizada, foi possível inferir que, tipicamente, para os participantes da pesquisa, um quarto de internação belo é colorido, com cores vivazes que variam do amarelo ao vermelho; possui móveis e layout interessantes, diferentes do usual, como é o caso dos leitos com proteções laterais em madeira, posicionados em modo desencontrado ou em baias; é bem equipado com TV e mobiliário de apoio, sem ser superlotado; possui janelas ou portas-janela amplas com cortinas, que oferecem adequada luz natural e possibilidade de contato com o exterior (acesso visual ou físico), especialmente 
com a natureza. Essas características puderam ser reconhecidas nos ambientes das fotografias I, G, K, J, identificados pelos pacientes como os mais belos no conjunto de imagens apresentadas.

\section{Conclusão}

O presente artigo apresentou a aplicação de técnicas fotográficas em duas investigações executadas em hospitais, dedicadas ao exame da restauração a partir da condição de estresse. A proposta metodológica trazida por essas experiências entende a fotografia como instrumento possível, em razão da potencialidade que demonstra em provocar deslocamentos e criar novos modos de olhar a realidade. Aliado a isso, configurase, do ponto de vista metodológico, como mecanismo de linguagem e produção de discurso sobre aspectos da realidade nem sempre visíveis ou dizíveis por outros modos.

Dentre o rol de aplicabilidade da fotografia em pesquisa científica, destacamos nesse artigo as possibilidades de usá-la como técnica. A amplitude e extensão passível de ser alcançada por intermédio de tal técnica perpassa o universo do relato verbal e da inferência de se transmitir ao leitor uma realidade reduzida a uma forma de olhar. A fotografia se revelou instrumento de linguagem acessível a diferentes faixas etárias, com o potencial de tornar atraente o processo investigativo.

Importante ressaltar que o uso da fotografia como simulador de ambientes pode não reproduzir as mesmas respostas psicofisiológicas desencadeadas no ambiente real. Entretanto, as pesquisas têm demonstrado que as divergências de resposta a partir das duas condições (real e simulado) não são significativas a ponto de desestimular o emprego da técnica. Aspectos relacionados à produção da fotografia, tais como foco, enquadramento, iluminação, cores, também deveriam ser considerados como variáveis intervenientes. Quando a técnica é empregada na função modelo, um ponto a ser considerado é a subjetividade do pesquisador na seleção e elaboração das imagens.

No que condiz ao diálogo entre os dois estudos apresentados, destaca-se a utilização da técnica fotográfica e suas diversas formas de uso para obtenção de material não verbal e verbal, repleto de conteúdo intrínseco. Ademais, a intervenção em hospitais proposta, considerando-se a peculiaridade da custódia e da faixa etária, indica uma oportunidade até então pouco explorada nacionalmente. Considerar as restrições dos contextos investigados não significa, necessariamente, reduzi-los a uma configuração sem elementos ambientais que despertem diferentes experiências sensoriais. Pode-se observar que, mesmo considerando as divergências entre clínica infantil e hospital de custódia e tratamento psiquiátrico, os enfoques e demandas descritas pelos participantes de ambos os estudos versam sobre melhorias possíveis e direcionadas a um ponto em comum e identificado pelos usuários dos lugares: a redução psicofisiológica do estresse.

Enquanto instrumento, a fotografia permite uma expressão do meio investigado, assim como explora e expande os dados obtidos em prol da melhor e mais completa forma de análise. Observa-se na foto um grande facilitador do discurso, que é enriquecido com os elementos visuais. Por fim, resta conjugar os verbos ousar, inovar e apreciar para que assim a fotografia se consolide como técnica de pesquisa. As experiências construídas até o momento indicam que as contribuições da imagem para os estudos psicológicos são inegáveis, e as perspectivas futuras, animadoras. 


\section{Notas}

[1] De acordo com Neiva-Silva e Koller (2002), o primeiro registro de uso da fotografia em pesquisa psicológica data da última década do século XIX. Esse período coincide com o próprio reconhecimento da Psicologia como disciplina científica.

[2] Para a pesquisa na bases de dados Science Direct e Sage, foram utilizados os descritores "photograph" OR "picture" OR "image" AND "restorativeenvironment" OR "restoration" OR "restorativeness", no título, resumo e palavras-chaves das publicações. Já nas bases Scielo e Pepsic, utilizaram para a busca as palavras "fotografia" OU "imagem" E "ambientes restauradores" OU "restauração" OU "restauratividade", em todos os campos das publicações. A pesquisa foi realizada em julho de 2016, sem parâmetro temporal. Artigos que utilizaram as expressões "restauração (ou restoration)" e "restauratividade (ou restorativeness)" com sentido diverso daquele objetivado foram excluídos da pesquisa.

[3] Estados de Consciência Alterados são estados separados da realidade diária normal de um indivíduo, caracterizados por alterações na cognição, percepção e expressão emocional (Kjellgren \& Buhrkall, 2012).

\section{Referências}

Bardin, L. (1977). Análise de conteúdo. Lisboa: Edições 70.

Berman, M. C., Jonides, J., \& Kaplan, S. (2008). The cognitive benefits of interacting with nature. Psychological Science, 19(12), 1207-1212. Recuperado de http://pss.sagepub.com/content/19/12/1207

Berto, R. (2005). Exposure to restorative environments helps restore attentional capacity. Journal of Environmental Psychology, 25(3), 249-259. Recuperado de http://www.sciencedirect.com/science/article/pii/S0272494405000381

Berto, R., Baroni, M.R., Zainagui, A., \& Bettella, S. (2010). An exploratory study of the effect of high and low fascination environments on attentional fatigue. Journal of Environmental Psychology, 30(4), 494500.Recuperado de http://www.sciencedirect.com/science/article/pii/S0272494409001054.

Berto, R., Massaccesi, S., \& Pasini, M. (2008). Do eye movement measured across high and low fascination photographs differ? Addressing Kaplan's fascination hypothesis. Journal of Environmental Psychology, 28(2), 185-191.Recuperado de http://www.sciencedirect.com/science/article/pii/S0272494407000977

Cavalcante, S., \& Maciel, R. H. (2008). Métodos de avaliação da percepção ambiental. In J. Q. Pinheiro, \& H. Günther (Orgs.). Métodos de pesquisa nos estudos pessoa-ambiente (pp. 149-180). São Paulo: Casa do Psicólogo.

Chang, C., Hammitt, W. E., Chen, P., Machnik, L., \& Su, M. (2008). Psychophysiological responses and restorative values of natural environments. Landscape and Urban Planning, 85(2), 79-84. Recuperado de http://www.sciencedirect.com/science/article/pii/S0169204607002459

Colombo, B., Laddaga, S., \& Antonietti, A. (2015). Psychology and design. The influence of the environment's representation over emotion and cognition. An ET study on Ikea design. Procedia Manifacturing, 3, 2259-2266.Recuperado de http://www.sciencedirect.com/science/article/pii/S2351978915003716

Felsten, G. (2009). Where to take a study break on the college campus: an attention restoration theory perspective. Journal of Environmental Psychology, 29(1), 160-167.Recuperado de http://www.sciencedirect.com/science/article/pii/S0272494408000996

Gomes, J. G. M., Cavalcante, S., \& Grinfeld, S. (2007). Sala de espera: estudo da percepção dos usuários de clínicas odontológicas. International Journal of Dentistry, 6(2), 39-50. Recuperado de https://www.ufpe.br/ijd/index.php/exemplo/article/viewArticle/15 
Hartig T., (2011). Issues in restorative environment research: matters of measurement. In B. FernándezRamírez, C. H. Villodres, C. M. S. Ferrer, \& J. M. Méndezm (Orgs.). Psicología ambiental 2011: entre los estudios urbanos y el análisis de la sostenibilidad (pp. 41-66). Almería: Universidad de Almería.

Hietanen, J. K., \& Korpela, K. M. (2004). Do both negative and positive environmental scenes elicit rapid affective processing? EnvironmentandBehavior, 36(4), 558-577. Recuperado de http://eab.sagepub.com/content/36/4/558.abstract.

Higuchi M. I. G., \& Kuhnen A. (2008). Percepção e representação ambiental: métodos e técnicas de investigação para a educação ambiental. In J. Q. Pinheiro, \& H. Günther (Orgs.). Métodos de pesquisa nos estudos pessoa-ambiente (pp. 181-215). São Paulo: Casa do Psicólogo.

Hubbard, P. (1996). Conflicting interpretations of architecture: an empirical investigation. Journal of Environmental Psychology, 16(2),75-62.Recuperado de http://www.sciencedirect.com/science/article/pii/S0272494496900079

Justo, J. S., \& Vasconcelos, M. S. (2009). Pensando a fotografia na pesquisa qualitativa em psicologia. Estudos e Pesquisas em Psicologia,9(3), 760-774. Recuperado de http://pepsic.bvsalud.org/pdf/epp/v9n3/v9n3a13.pdf.

Kjellgren, A., \& Buhrkall, H. (2012). A comparison of the restorative effect of a natural environment with that of a simulated natural environment. Journal of Environmental Psychology, 30(4), 464-472. Recuperado de http://www.sciencedirect.com/science/article/pii/S0272494410000204.

Korpella, K. M., Klemetilä, T., \& Hietanen, J. K. (2002). Evidence for rapid affective evaluation of environmental scenes. Environment and Behavior, 34(5), 634-650. Recuperado de http://eab.sagepub.com/content/34/5/634.short.

Kort, Y. \& Ijsselsteijn, W. A. (2006). Reality check: the role of realism in stress reduction using media technology. CyberPsychology \& Behavior, 9(2), 230-233. Recuperado de http://online.liebertpub.com/doi/abs/10.1089/cpb.2006.9.230.

Kort, Y. A. W., Meijnders, A. L., Sponsele, A. A. G., \& ljsselstein, W. A. (2006). What's wrong with virtual trees? Restoring from stress in a mediated environment. Journal of Environmental Psychology, 26(4), 309320.Recuperado de http://www.sciencedirect.com/science/article/pii/S0272494406000570.

Kuhnen, A. (2004). Lagoa da Conceição: meio ambiente e modos de vida em transformação. Florianópolis: CidadeFutura.

Lee, K. E., Williams, K. J. H., Sargent, L. D., Farrel, C., \& Williams, N.S. (2014). Living roof preference is influenced by plant characteristics and diversity. Landscape and Urban Planning, 122, 152-159. Recuperado de http://www.sciencedirect.com/science/article/pii/S0169204613001904.

Lindal, P. J., \& Hartig, T. (2015). Effects of urban street vegetation on judgments of restoration likelihood. UrbanForestry\&UrbanGreening,14(2), 200-209. Recuperado de http://www.sciencedirect.com/science/article/pii/S1618866715000084.

Loizos, P. (2002). Vídeo, filme e fotografias como documentos de pesquisa. In M. W. Bauer \& G. Gaskell (Orgs.). Pesquisa qualitativa com texto, imagem e som (pp. 137-155). Petrópolis: Vozes.

Lymeus, F., Lundgren, T., \& Hartig, T. (2016). Attentional efforts of beginning mindfulness training is offset with practice directed toward images of natural scenery. EnvironmentandBehavior, 1-24. Recuperado de http://eab.sagepub.com/content/early/2016/07/08/0013916516657390.abstract

Maurente, V., \& Tittoni, J. (2007). Imagens como estratégia metodológica em pesquisa: a fotocomposição e outros caminhos possíveis. Psicologia e Sociedade, 19(3), 33-38.Recuperado de http://www.scielo.br/scielo.php?script=sci_arttext\&pid=S0102-71822007000300006.

Neiva-Silva, L., \& Koller, S. H. (2002). O uso da fotografia na pesquisa em Psicologia. Estudos de Psicologia, 7(2), 237-250. Recuperado de http://www.scielo.br/pdf/epsic/v7n2/a05v07n2.pdf.

Nejati, A., Rodiek, S., \& Shepley, M. (2016). Using visual simulation to evaluate restorative qualities of access to nature in hospital staff break areas. Landscape and Urban Planning, 148, 152-159. Recuperado de http://www.sciencedirect.com/science/article/pii/S0169204615002546. 
Pinheiro, J. Q., Elali, G. A., \& Fernandes, O. S. (2008). Observando a interação pessoa-ambiente: vestígios ambientais e mapeamento comportamental. In J. Q. Pinheiro \& H. Günther (Orgs.). Métodos de pesquisa nos estudos pessoa-ambiente (pp. 75-104). São Paulo: Casa do Psicólogo.

Tang, I., Sullivan, W. C., \& Chang, C. (2015). Perceptual evaluation of natural landscapes: the role of the individual connection to nature. Environment and Behavior, 47(6), 595-617.Recuperado de http://eab.sagepub.com/content/47/6/595.

Valtchanov, D., Barton, K., \& Ellard, C. (2010). Restorative effects of virtual nature settings. Cyberpsychology, Behavior, and Social Networking, 13(5), 503-512. Recuperado de http://online.liebertpub.com/doi/abs/10.1089/cyber.2009.0308.

Valtchanov, D., \& Ellard, C.G. (2015). Cognitive and affective responses to natural scenes: effects of low level visual properties on preference, cognitive load and eye-movements. Journal of Environmental Psychology, 43, 184-195.Recuperado de http://www.sciencedirect.com/science/article/pii/S0272494415300220.

Villagra-Islas, P., \& Alves, S. (2016). Open space and their attributes, uses and restorative qualities in an earthquake emergency scenario: the case of Concepcion, Chile. Urban Forestry and Urban Greening, 19, 56-67. Recuperado de http://www.sciencedirect.com/science/article/pii/S1618866715300571.

Watts, G., Khen, A., \& Pheasant, R. (2016). Influence of soundscape and interior design on anxiety and perceived tranquillity of patients in a healthcare setting. Applied Acoustics, 104, 135-141. Recuperado de http://www.sciencedirect.com/science/article/pii/S0003682X15003230.

White, E., \& Gatersleben, B. (2011). Greenery on residential buildings: does it affect preferences and perceptions of beauty? Journal of Environmental Psychology, 31(1), 89-98. Recuperado de http://www.sciencedirect.com/science/article/pii/S027249441000099X.

White, M., Smith, A., Humprhryes, K., Pahl, S., \& Snelling, D. (2010). Blue space: the importance of water for preference, affect, and restorativeness ratings of natural and built scenes. Journal of Environmental Psychology, 30(4), 482-493. Recuperado de http://www.sciencedirect.com/science/article/pii/S0272494410000496.

Wyles, K.J., Pahl, S., Thomas, K., \& Thompson, R.C. (2015). Factors that can undermine the psychological benefits of coastal environments: exploring the effect of tidal state, presence, and type of litter. EnvironmentandBehavior, 1-32. Recuperado de http://eab.sagepub.com/content/early/2015/07/15/0013916515592177.abstract. 